\title{
RECURSOS E ESTRATÉGIAS EM SAÚDE: SABERES E PRÁTICAS DE MULHERES DOS SEGMENTOS POPULARES
}

\author{
Edir Nei Teixeira Mandu* \\ Graciette Borges da Silva**
}

MANDÚ, E.N.T.; SILVA, G.B.da. Recursos e estratégias em saúde: saberes e práticas de mulheres dos segmentos populares. Rev.atino-am.enfermagem, Ribeirão Preto, v. 8, n. 4, p. 15-21, agosto 2000.

Neste artigo, refletimos sobre os recursos e estratégias em saúde, paralelos à prática médica "oficial", utilizados por um segmento de mulheres pobres brasileiras, que vive em uma dada realidade. Na investigação, de cunho qualitativo, utilizamos as representações sociais como categoria central de análise, entendidas como parte das relações sociais contraditórias e da história coletiva dos grupos. Focalizamos o modo particular com que mulheres consumidoras dos serviços públicos de saúde reafirmam e, ao mesmo tempo, negam seu próprio saber/fazer, em contraponto à prática médica dominante, a partir da utilização de um conjunto variado de recursos e estratégias em saúde, que incluem medidas como a medicina caseira, as práticas médicoreligiosas, a auto-medicação, a consulta ao "farmacêutico" e orientações junto a agentes locais de saúde.

UNITERMOS: saúde da mulher, saúde pública, recursos em saúde

\section{INTRODUÇÃO}

As reflexões apresentadas aqui constituem-se parte de uma investigação mais ampla realizada junto a mulheres das camadas populares, residentes em Cuiabá, capital de Mato Grosso, que toma como tema central os seus saberes, vivências e demandas em saúde. Especificamente, neste artigo, discutimos as práticas "populares" em saúde de que se utilizam e o modo particular como, através delas, ao mesmo tempo, reforçam os saberes e práticas dominantes em saúde e a eles resistem.

Participaram da investigação onze mulheres com idade entre 20 e 59 anos de idade, cujo perfil social, embora heterogêneo, permite caracterizá-las como trabalhadoras dos segmentos pobres do país: seu nível de escolaridade, no momento do levantamento dos dados, localizava-se entre o analfabetismo e o segundo grau completo; a renda familiar de que dispunham variava entre menos que um e dez salários mínimos (na época, o salário mínimo correspondia a aproximadamente 60 dólares); todas dependiam dos serviços públicos de saúde.

$\mathrm{O}$ espaço físico-social onde foi realizada a investigação é o de um bairro periférico de Cuiabá, denominado Pascoal Ramos***, que constitui parte da área que compõe o Distrito Sanitário Sul (um dos quatro existentes no município). $\mathrm{O}$ atendimento em saúde da população local, além de ter suporte nesse Distrito, é complementado por serviços localizados nos demais.

Com base em GRAMSCI (1991), partimos do pressuposto mais geral de que os conhecimentos, valores e práticas dos segmentos populares refletem uma cultura própria, em que se encontram valores tradicionais atualizados e componentes da sua história de vida, marcados pelo lugar que ocupam no mundo do trabalho e relações sociais. Interpretamos que as idéias dos grupos populares estão comprometidas com a sua condição de classe, revelando contradições presentes na sociedade vividas no plano das relações de produção.

CHAUÍ (1993), reforçando essas idéias, observa que as representações sociais dos segmentos populares são resultantes de uma mistura de idéias dos grupos de elite com idéias próprias, que ganham uma identidade particular revelada através de conteúdos de conformismo e de núcleos de resistência.

De igual modo, MINAYO \& SOUZA (1989)

\footnotetext{
* Enfermeira. Professor Adjunto da Faculdade de Enfermagem e Nutrição da Universidade Federal de Mato Grosso. Doutoranda em Enfermagem da Escola de Enfermagem de Ribeirão Preto da Universidade de São Paulo

** Socióloga. Professor Associado (aposentado) junto ao Departamento de Enfermagem Psiquiátrica e Ciências Humanas da Escola de Enfermagem de Ribeirão Preto da Universidade de São Paulo

*** Bairro Pascoal Ramos: área com características rurais até início dos anos 80; com 372 domicílios (Fundação IBGE, 1991); com escola de $1^{\circ}$ e $2^{\circ}$ graus, creche, centro de saúde local, pequeno comércio de alimentação, farmácia, correio, posto policial, igrejas; entre seus moradores encontram-se vários benzedores e raizeiros
} 
consideram que, frente às contradições do sistema capitalista, os conhecimentos e vivências em saúde desses grupos expressam elementos dominantes no setor, não se limitando, porém, à sua reprodução, mas abrangendo assimilações, reelaborações, recusa e oposição ao saber/ fazer médico.

Assim, os valores e práticas de mulheres dos segmentos populares relativos aos cuidados em saúde, apresentados aqui, revelam o modo peculiar do grupo colocar-se frente à saúde-doença e ao processo de cura.

A consideração a esses valores e vivências e às suas bases materiais é imprescindível à promoção da saúde. Ainda que a dimensão simbólica não conforme diretamente a prática dos diferentes grupos (HERZLICH, 1991), a valorização desse universo e suas especificidades é fundamental, pois possibilita identificar/compreender e considerar, no encaminhamento de práticas profissionais, elementos dinamizadores da realidade vivida - de conformação, recusa e reelaboração de construções historicamente oficializadas no campo da saúde.

\section{PROCESSO DE INVESTIGAÇÃO}

O estudo, do qual faz parte os achados que apresentamos, foi desenvolvido dentro do referencial da pesquisa qualitativa, privilegiando os discursos dos sujeitos como fonte de informação sem, contudo, restringir a eles a análise. Foram eleitas, para compor o grupo de pesquisa, consumidoras dos serviços públicos de saúde residentes no bairro mencionado. Participaram como informantes onze mulheres, entre elas, duas representantes de grupos comunitários locais e três trabalhadoras do Centro de Saúde Local (referências junto à população para atendimento informal em saúde).

O levantamento dos dados, relativos à realidade concreta das pesquisadas, foi feito a partir de observações diretas (de condições sociais locais e práticas em saúde adotadas) e de entrevistas semi-estruturadas (focalizando suas vivências e valores). A análise e divulgação desses dados foram autorizadas pelas mulheres selecionadas e sobre estes assumimos inteira responsabilidade.

Como caminho para as análises adotamos as orientações de MINAYO (1993) e GOMES (1994), baseadas na hermenêutica-dialética, em que, coerentemente com os pressupostos assumidos, a fala dos sujeitos é vista como expressão cultural, marcada pelo tempo histórico e ideologia presente na sociedade, refletindo as relações sociais contraditórias. Assim, desenvolvemos um processo de interpretação que incluiu: - o estudo inicial das condições de vida do grupo, utilizado na contextualização do estudo;

- a elaboração prévia de categorias analíticas (representações sociais de saúde-doença, representações sociais acerca da atenção à saúde****);

- a construção de categorias empíricas a partir dos dados levantados nas entrevistas (aqui, são trabalhadas as relacionadas aos recursos "populares" utilizados e especificidades em seu uso);

- um movimento constante entre o empírico e o teórico; - a associação entre base material e comunicação do grupo.

Na categorização do material empírico, com base em GOMES (1994), encaminhamos a ordenação dos dados, a sua classificação minuciosa e a formação de conjuntos de informações (categorização empírica), segundo a heterogeneidade das comunicações e questões postas para o estudo.

\section{RECURSOS POPULARES NO CAMPO DA SAÚDE-DOENÇA}

A análise dos dados empíricos colhidos junto às mulheres que participaram deste estudo, permitiu-nos identificar que, na satisfação das suas necessidades no campo da saúde-doença bem como das de sua família, elas se utilizam de um conjunto variado de recursos e estratégias em saúde. Tais recursos incluem, além da utilização de serviços de saúde públicos e privados, o uso de medidas "populares" como a medicina caseira, as práticas médico-religiosas, a auto-medicação, a consulta ao "farmacêutico" e a busca de orientação junto a agentes locais de saúde.

\section{A medicina caseira}

Constatamos que a utilização dos serviços de saúde, públicos e eventualmente privados, é parte das experiências e do modo particular com que as mulheres deste estudo concebem os problemas em saúde e o seu enfrentamento.

Tal utilização reflete, em alguma medida, a crescente influência da medicalização nas representações e práticas em saúde-doença presentes entre as camadas mais pobres da população (MINAYO, 1988), reflexo dos processos mais gerais de absorção de valores dominantes em saúde, trabalhados nas várias relações sociais presentes sobretudo no espaço urbano das sociedades capitalistas.

**** São apresentadas neste artigo apenas parte dos dados empíricos relacionados à categoria analítica representações no campo da atenção à saúde - os referentes às práticas "populares" 
Entre as entrevistadas, identificamos que os cuidados em saúde-doença são vistos como dependentes dos serviços médicos, visão expressa mediante a referência a um conjunto de percepções, demandas e experiências $* * * * *$, que refletem uma certa absorção do padrão médico que se legitimou no campo da saúde, especialmente a partir do século XIX.

Contudo, medidas "populares", historicamente presentes entre esses segmentos, também fazem parte das vivências dessas mulheres, uma vez que se utilizavam de outras medidas que não a medicina "oficial".

Segundo MINAYO (1988), as práticas e os discursos dos grupos populares no campo da saúdedoença revelam elementos presentes na cultura dominante, mediados pelo saber e prática médica, e também componentes da história passada, manifesta de modo novo.

CARRARA (1982) chama atenção para o fato de que as práticas de medicina popular ainda sobrevivem, sobretudo porque têm raízes profundas na consciência dos segmentos populares, que reconhecem a sua eficácia e legitimidade.

Assim, entre as mulheres que participaram do estudo encontramos o uso constante de remédios e medidas caseiras, chamados, aqui, de medicina caseira, tradicionalmente utilizados pelos grupos populares. Entre elas, esta é uma prática comum, utilizada tanto como primeiro recurso em saúde - em situações consideradas mais simples, quanto como recurso complementar ou alternativo a outros do campo médico.

Há, no entanto, para elas, problemas em saúde que somente o recurso médico pode resolver. No repertório de doenças que identificam e tratam, as mais graves, ou melhor, as percebidas como tal, são atribuídas como de responsabilidade médica, por entenderem que elas só se resolvem mediante os meios e instrumentos terapêuticos da medicina "oficial".

Contudo, em seu cotidiano, como percebemos observando algumas de suas práticas e através de seus discursos, utilizam-se de uma variedade bastante ampla de elementos naturais vegetais (folhas, cascas, raízes de plantas variadas, frutas, sementes) e animais (mel, ovos, gordura). Usam medicinais de modo específico, através de um conjunto de meios e processos "terapêuticos", como banhos, bebidas, cozimentos e aplicações à pele, na prevenção e tratamento dos mais variados processos de saúde-doença.

Todas as mulheres entrevistadas creditam aos remédios caseiros resultados satisfatórios, embora mais lentos, frente aos problemas para os quais os utilizam. Seus efeitos no organismo são considerados como mais saudáveis em relação aos remédios farmacêuticos, vistos como "fortes e pesados" e capazes de gerar, no organismo, efeitos indesejáveis.

Tais concepções permitem constatar um modo muito próprio de pensar e agir frente à prevenção e cura, revelador de uma certa autonomia, embora seja comum, entre elas, a utilização de remédios caseiros associados a produtos industrializados (como, por exemplo, o açúcar) e/ou a medicamentos farmacêuticos, a partir de conhecimentos adquiridos no contato com o campo médico.

Os saberes e práticas das entrevistadas indicam que, ao lado de uma certa introjeção da visão e prática medicalizada em saúde, mantêm-se fortemente valores tradicionais, como o da medicina caseira, retraduzidos segundo as experiências presentes. Há uma certa imbricação dessas práticas em seu cotidiano, tanto que usam remédios caseiros, em certas situações, de forma complementar à medicina "oficial".

Identificamos também que a medicina caseira, mantida de forma renovada, apresenta-se, em certos momentos, como recusa à racionalidade e poder médicos sobre a própria vida. Nos depoimentos analisados, encontramos, com certa força, a legitimação, pelas mulheres, do seu próprio saber em saúde-doença quando, através da valorização das práticas caseiras em contraposição às práticas médicas "científicas", apontaram a superioridade daquela, elegendo seus próprios saberes como de igual ou maior valor, recusandose a tê-los desvalorizados.

Notamos que, por um lado, valorizam e delegam os cuidados em saúde aos serviços e, mais especificamente, aos profissionais médicos e, por outro, mantêm a propriedade da avaliação e cura em suas próprias mãos, e o fazem de modo particular através da medicina caseira. Assim, resgatam, de certa forma, o poder sobre seus próprios corpos, recusando elementos impostos pela medicina "oficial".

Uma das razões que justifica o uso que fazem dos remédios caseiros é o acesso mais fácil a eles, uma vez que para obtê-los, cultivam-nos ou recorrem a vizinhos, benzedores e raizeiros que, na maioria das vezes, não cobram por eles. A sua utilização depende de conhecimentos de pessoas experientes da família, da procura de "peritos" da própria comunidade (ou de outras) e também do uso de informações obtidas através dos meios de comunicação, que compõem um estoque de conhecimentos nesse campo.

Os depoimentos permitem reconhecer a medicina caseira como uma prática alternativa aos vazios deixados pelo sistema de saúde. CARRARA (1982); LAPLATINE

***** A especificação dessas percepções, demandas e experiências são apresentadas em MANDÚ, E.N.T.; SILVA, G.B. Assistência pública à saúde: mulheres com a palavra. Revista da Escola de Enfermagem da USP. São Paulo, v. 32, n. 3, out. de 1998 
\& RABEYRON (1989), discutindo as práticas medicinais populares, reconhecem que seu sucesso, em parte, decorre das carências e fracassos da medicina positiva. Assim, também encontramos que, as dificuldades de acesso aos serviços de saúde, a qualidade que não responde às expectativas e demandas, os custos econômicos necessários ao deslocamento para serviços mais completos e para a execução dos tratamentos indicados, que nem sempre podem ser absorvidos pelas mulheres que participaram desta investigação, são "superados" pelo uso de medidas e remédios caseiros, recursos que encontram facilmente nos locais onde vivem, que resolvem muitos de seus problemas em saúde e que, economicamente, lhes são mais acessíveis.

\section{Práticas médico-religiosas}

À medicina caseira soma-se o recurso das práticas médico-religiosas - práticas cristãs e contatos com benzedores. Rezas, orações, benzimentos, seja como primeira medida, como alternativa complementar ou como último recurso à falta de respostas através dos meios materiais conhecidos, são usados freqüentemente pelas mulheres em foco.

Não há, contudo, homogeneidade em suas práticas. Os benzimentos não recebem o crédito de todas, chegando a ser considerados inaceitáveis, ignorância ou força não controlável, refletindo valores especialmente trabalhados pelas religiões cristãs das quais participam. As que procuram benzedores, todavia, vêem-se favorecidas tanto por uma comunicação que consideram acessível, decorrente de representações em comum sobre saúde-doença, quanto por um cotidiano compartilhado, que as aproxima e lhes permite uma certa identificação com aqueles.

A religiosidade que perpassa o discurso apresentado nas entrevistas apresenta a explicação/ solução dos problemas em saúde-doença num campo que engloba a dimensão sobrenatural.

Para MINAYO (1988), a religiosidade presente no campo da saúde-doença tem raízes históricas profundas, manifesta pelos vários grupos sociais de modo renovado, sobretudo no espaço urbano.

Contudo, a explicação religiosa tem sido interpretada como fruto da absorção da ideologia dominante, via religiões, que, visando a um mascaramento da construção social da realidade, apresenta a saúdedoença como decorrente da vontade divina.

Sem negar que as religiões têm de fato contribuído para tal ocultamento, parece que a contribuição de CHAUÍ (1993) mostra-se mais adequada à interpretação do que essas significam para os grupos populares e, especificamente, para as mulheres entrevistadas. A religiosidade apresenta-se como uma resposta desses grupos à adversidade social e política, referida à injustiça do mundo, indicando o desejo de mudanças, exprimindo o sentimento de fraqueza em relação aos opressores e a visualização da possibilidade de alteração da ordem pela união de todos. Como ela própria observa:

"as religiões se oferecem não só como paliativos para as desgraças reais de um cotidiano percebido como sem saída (o famoso 'ópio do povo') mas também como elaboração realista e consciente das adversidades do cotidiano, funcionando como pólo de resistência numa sociedade onde a cidadania foi recusada para a maioria e onde a opressão é a regra da existência social das camadas populares" (p. 81).

A resistência revela-se no desejo de que a vida seja diferente, não tão sofrida como é para os que vivem em meio a tantas carências. A religiosidade resgata uma condição de igualdade que esses grupos não vivenciam em seu cotidiano, razão pela qual reafirmam sua importância.

Assim, a religiosidade encontrada entre as depoentes, antes que fatalismo apenas, que revela subordinação, é percepção das carências e injustiças vividas e desejo de igualdade, caracterizando-se, mais propriamente, como negação da ordem estabelecida.

A religiosidade e sua interligação com as questões de saúde-doença também é vista como parte da cultura tradicional dos grupos populares, ligada à sua visão acerca do homem e seu destino (MINAYO, 1988). Da visão mais ampla que os vários grupos sociais possuem acerca da vida e morte derivam as suas práticas no campo religioso e, particularmente, no da saúde.

De outra forma, reconheceu-se nos depoimentos que, na busca de proteção e cura, as práticas médicoreligiosas são utilizadas quando não se obtêm respostas a problemas vividos através da prática médica. Também não é incomum o seu uso junto a outros recursos, embora, em certos momentos, seja ela a eleita como alternativa para problemas que o campo médico, apesar de todo o seu "conhecimento", não pode resolver por não estar em sua esfera de atuação.

\section{A auto-medicação e a orientação junto a "farmacêuticos"}

Outros recursos utilizados pelas mulheres entrevistadas são a auto-medicação e a busca de orientação junto aos "farmacêuticos" (no geral, vendedores ou donos das farmácias). Apesar de algumas delas se referirem ao risco da auto-medicação e uso da 
"receita de farmácia" sem uma prévia avaliação e indicação de tratamento médico, todas realizam essa prática em um ou outro momento.

A auto-medicação é favorecida pelos conhecimentos adquiridos em situações anteriores ou sob a influência da propaganda, influenciada pela medicalização em saúde. O uso deste recurso, como os demais apresentados, também se revela alternativo a situações em que os serviços não correspondem às necessidades e demandas das entrevistadas. Um contato mais próximo com os vendedores das farmácias, em geral pessoas que vivem na comunidade, tornam mais rápido o acesso a "respostas" requeridas.

QUEIROZ (1991) menciona o prestígio tradicionalmente conferido pelos grupos populares ao "farmacêutico", especialmente em função de uma certa proximidade de elementos culturais entre eles, que acaba por favorecer a sua procura.

Além disso, identifica-se que a população busca uma resposta mais rápida e imediata para seus problemas de saúde, coerentemente com a visão normativa de recomposição imediata de seus corpos para o trabalho (BOLTANSKI, 1989), em que o uso de remédios alopáticos é percebido como mais apropriado.

O complexo médico-industrial, especialmente através da propaganda, estimula constantemente a prática da auto-medicação, indicando remédios a partir da apresentação de seus resultados "milagrosos" e a própria prática nos serviços de saúde não se furta a estimular o uso de medicamentos, pois geralmente o sujeito que procura os serviços de saúde deles não sai sem uma receita médica.

Contudo, o crédito dado ao uso de medicamentos farmacêuticos não ocorre sem conflitos. A medicação farmacêutica requisitada e utilizada pelas mulheres entrevistadas é também recusada em certos momentos, atribuindo-se a ela efeitos danosos sobre o corpo. A lógica do consumo, que está por detrás da indicação de medicamentos, consumo este estimulado pelas próprias farmácias que não se negam a "medicar", também é, em certos momentos, percebida e confrontada.

Por outro lado, a insatisfação manifesta com os serviços de saúde, sobretudo os da rede pública, funciona igualmente como um estímulo à prática da automedicação e busca de "tratamento" junto ao farmacêutico ou balconista. Sabe-se que a prática médica "oficial", apesar de se considerar a única com competência para avaliar e medicar, freqüentemente se recusa a dar atenção ao que considera problema "insignificante" (os que não se enquadram dentro de suas classificações). Esta postura acaba por forçar a população e, especificamente, as mulheres que participaram deste estudo a irem atrás de outros recursos (auto-medicação e consulta ao "farmacêutico"), buscando resolver problemas "mais" conhecidos ou para os quais não tiveram espaço nos serviços.

\section{Os agentes de saúde como recurso}

Recorrer a profissionais locais de saúde, que residem no próprio bairro, e a pessoas consideradas mais experientes (agentes de saúde), também faz parte das estratégias utilizadas pelas mulheres em foco. Os agentes de saúde que residem no bairro (neste estudo, pessoas com preparo junto ao campo médico "oficial" e pessoas consideradas amigas e mais preparadas) são vistos por elas como uma das alternativas de atenção à saúde.

Segundo seus depoimentos, as trocas, nesse campo, no geral, são favorecidas pela amizade, pelo compartilhamento dos mesmos códigos e problemas comunitários. As dificuldades de comunicação que vivenciam no contato com os serviços, especialmente com relação ao profissional médico, são em parte superadas junto a esses agentes.

A vida compartilhada e, ao mesmo tempo, a experiência dos agentes de saúde junto à prática médica "oficial" parecem oferecer os elementos necessários ao crédito que neles depositam. As falas apresentadas revelam a valorização que dão àqueles que vivem uma vida semelhante as suas e que, ao mesmo tempo, possuem conhecimentos legitimados socialmente.

Ao que nos parece, a procura desses agentes para resoluções de problemas em saúde, em alguma medida, expressa a possibilidade que as mulheres encontram de unirem dois aspectos relativos à atenção médica que valorizam, a proximidade/acolhimento e o acesso ao conhecimento "científico".

Talvez isto justifique a penetração que agentes locais de saúde têm junto a grupos populares. Não que isso ocorra sem conflito, tanto que, em determinados momentos, algumas das mulheres que recorrem a esses agentes referem, nas entrevistas, uma certa percepção de que eles se "sentem superiores" e, ao contrário, entrevistadas que são também agentes de saúde, por vezes falam da sua comunidade como "a população", como se dela não fizessem parte.

\section{Auto-produção de cuidados em saúde}

As vivências e percepções encontradas em relação à atenção em saúde revelam as participantes deste estudo não só como consumidoras de recursos e serviços em saúde, mas também como produtoras de saúde em seu próprio meio. Elas possuem um conjunto de conhecimentos e práticas que aplicam as suas próprias necessidades, no cuidado de sua família, de vizinhos, de amigos e conhecidos de sua comunidade.

Avaliam situações de saúde-doença, identificam 
graus de gravidade dos problemas vividos e os riscos presentes e, quando julgam necessário, procuram (ou encaminham a) diferentes recursos em saúde. Além disso, identificam causas, diagnosticam, definem e aplicam cuidados e tratamentos, resolvendo, elas mesmas, certas situações.

Os seus conhecimentos e práticas possuem características próprias e se organizam a partir de conhecimentos tradicionais adquiridos junto a familiares, junto a pessoas com as quais compartilham suas vidas, a partir das suas próprias experiências e contatos com a medicina "oficial" e sistemas de comunicação, que reforçam ou não valores dominantes.

Essas mulheres vão construindo o seu saber e agindo, através das suas vivências e trocas culturais, referidas às suas experiências na família, no mundo do trabalho, nos contatos com instituições externas, no interior da classe dominada a qual pertencem. Nesse sentido, DIAS (1991) considera que:

"as mulheres apreendem, constróem e repassam seus conhecimentos, seu saber como agentes de saúde, condição inerente à sua situação de classe trabalhadora, a partir de suas experiências de vida diária na família, que de forma alguma é uma ilha fechada às interferências da vida social: através do mundo do trabalho do marido, dos filhos e delas próprias, através dos meios de comunicação de massa, nos contatos com agentes e instituições externas, a partir de suas vivências no bairro e no seio da classe dominada a que pertencem" (p. 96).

Os seus conhecimentos e práticas são influenciados pelo saber médico, com o qual têm contato direto ou indireto através de outras instituições e processos (como os meios de comunicação). Esse saber é absorvido e incorporado aos seus conhecimentos, valores e práticas como agentes de saúde, mas de forma recriada, segundo as suas necessidades, interesses, possibilidades e limites postos pela própria condição de carência em que vivem.

As condições restritivas de vida que enfrentam é substrato em que constróem seu saber e prática. Frente às carências, exploram os recursos de que dispõem, dividindo e, ao mesmo tempo, aproveitando-se de saberes e práticas existentes no campo da saúde-doença.

Essas mulheres não só aprendem através dos contatos e experiências que têm, como também repassam os seus conhecimentos dentro da comunidade em que vivem. Têm sempre uma opinião, uma suspeita ou uma indicação em relação às várias situações de saúde-doença que lhes são próximas.
Elas também se dispõem, de modo bastante solidário, a ajudar quem precisa de cuidados. O compartilhamento de uma realidade de desigualdades e carências, os limites de acesso que enfrentam em relação a bens e serviços coletivos, a falta de respostas sociais aos seus problemas, são todos fatores que parecem mobilizá-las a uma vida mais solidária. Observamos, na convivência com elas, que dividem com membros de sua comunidade dores, sofrimentos e necessidades, apoiandose mutuamente.

\section{CONSIDERAÇÕES FINAIS}

Constatamos que as mulheres deste estudo, como consumidoras ou como agentes de saúde, utilizam-se de uma série de conhecimentos e estratégias na manutenção e recuperação da própria saúde, da de sua família e grupo de convivência, entre os quais se incluem medidas tradicionalmente utilizadas por grupos populares.

Não possuem um saber coerente e organizado ou respostas para as variadas situações de saúde-doença, mas têm conhecimentos próprios e significativos, que lhes permitem enfrentar problemas nesse campo. O modo particular com que concebem os problemas em saúde e a cura, assim como os recursos a que têm ou não acesso, levam-nas a recorrer e a justificar a importância dos variados processos de que se utilizam.

Como produtoras ou consumidoras de atenção à saúde revelam não só adesão aos conhecimentos e práticas do campo médico, mas também resistência a eles, particularmente através da valorização e utilização de medidas "populares".

Enquanto os serviços de saúde as ignoram em sua condição de agentes, com saberes e experiências próprias, elas tecem, em seu cotidiano, um conjunto de teorias e interferências frente à globalidade de suas vidas, contrapondo-se não só à visão parcelar da medicina "oficial", mas também à sua suposta legitimidade como meio de preservação e recuperação da saúde. Se, por um lado, a medicina legitimou-se como prática científica/ oficial, com autoridade e monopólio para definir/ normatizar acerca da saúde-doença-cura, e, inclusive, enquadrou as práticas em saúde das camadas populares como não científicas/populares, apontando-as como não legítimas, por outro, essas práticas continuam bem vivas junto a esses grupos, num convívio mútuo com a chamada medicina "oficial". 


\section{HEALTH RESOURCES AND STRATEGIES: KNOWLEDGE AND PRACTICES OF WOMEN FROM POPULAR SEGMENTS}

This study presents a reflection on the health resources and strategies used by poor Brazilian women and that coexist with "official" medical practices. For this qualitative research, the authors applied social representation categories as central categories of analysis, which were understood as part of contradictory social relations and of the collective history of the groups. The peculiar way by which popular segments reaffirm and, at the same time, deny their own knowledgelaction as a counterpoint to the dominant medical practices is brought into focus, beginning from the utilization of a varied set of health resources and strategies that include measures such as household-medicine, medical and religious practices, self-medication, consultations with "pharmacists" and orientation by local health agents.

KEY WORDS: women's health, public health, health resources

\section{RECURSOS Y ESTRATEGIAS EN SALUD: SABERES Y PRÁCTICAS DE MUJERES DE SEG- MENTOS POPULARES}

En este articulo reflexionamos sobre los recursos y estrategias en salud, paralelos a la práctica medica oficial, utilizados por un segmento de mujeres pobres brasileñas que viven en una realidad dada. Los autores utilizan las representaciones sociales como categoría de análisis, traducidas como parte de las relaciones sociales contradictorias y de la historia colectiva de los grupos. Se focaliza el modo particular con que los segmentos populares reafirman y al mismo tiempo niegan su proprio saber/ hacer, en contradicción con la práctica médica dominante, a partir de la utilización de un conjunto variado de los recursos y estrategias en salud, como la medicina casera, practicas médico-religiosas, la auto-medicación, la consulta al "farmacéutico" y la búsqueda de orientación por medio de los agentes locales de la salud.

TÉRMINOS CLAVES: salud de la mujer, salud pública, recursos en salud

\section{REFERÊNCIAS BIBLIOGRÁFICAS}

01. BOLTANSKI, L. As classes sociais e o corpo. Tradução por Regina E. Machado. 3. ed. Rio de Janeiro: Graal, 1989.

02. CARRARA, D. A medicina popular. In: GENTILE DE MELO, C.; CARRARA, D. Saúde oficial, medicina popular. Rio de Janeiro: Editora Marco Zero, 1982. p. 49-114.

03. CHAUÍ, M. Conformismo e resistência: aspectos da cultura popular no Brasil. 5. ed. São Paulo: Brasiliense, 1993.

04. DIAS, N.M.de O. Mulheres "sanitaristas de pés descalços". São Paulo: Hucitec, 1991.

05. GOMES, R. Análise de dados em pesquisa qualitativa. In: MINAYO, M.C.de S. (Org.) Pesquisa social: teoria, método e criatividade. Petrópolis: Vozes, 1994. Cap. 4, p. 67-80.

06. GRAMSCI, A. Concepção dialética da história. 9. ed. Rio de Janeiro: Civilização Brasileira, 1991.
07. HERZLICH, C. A problemática da representação social e sua utilidade no campo da doença. Physis: Revista de Saúde Coletiva, Rio de Janeiro, v. 1, n. 2, p. 23-36, 1991.

08. LAPlatine, F.; RABEYRON, P.L. Medicinas paralelas. São Paulo: Brasiliense, 1989.

09. MINAYO, M.C.de S. Saúde-doença: uma concepção popular da etiologia. Cadernos de Saúde Pública, Rio de Janeiro, v.4, n. 4, 356-362, out/ dez. 1988.

10. MINAYO, M.C.de S. O desafio do conhecimento: pesquisa qualitativa em saúde. 2. ed. São Paulo: Hucitec, 1993.

11. MINAYO, M.C.de S.; SOUZA, H.de O. Na dor do corpo, o grito da vida. In: COSTA, N.do R. et al. (orgs.) Demandas populares, políticas públicas e saúde: movimentos sociais e cidadania. Petrópolis: Vozes, 1989. v. 2, p. 75-101. (Coleção Saúde e Realidade).

12. QUEIROZ, M.de S. Representações sobre saúde e doença: agentes de cura e pacientes no contexto do SUDS. Campinas: UNICAMP, 1991. 